\title{
Comparison of In Vitro Dissolution Profiles of Oxcarbazepine-HP $\beta$-CD Tablet Formulations with Marketed Oxcarbazepine Tablets
}

\author{
Nirav Patel ${ }^{1,5}$, Narendra Chotai ${ }^{2}$, Jayvadan Patel ${ }^{3}$, Tejal Soni ${ }^{1}$, \\ Julan Desai ${ }^{1}$, and Rajnikant Patel ${ }^{4}$ \\ 'Anand Pharmacy College, Opp. Town Hall, Nr, Grid. Anand, Gujarat, India \\ ${ }^{2}$ A. R. College of Pharmacy \& G. H. Patel Institute of Pharmacy, Vallabh Vidyanagar, Gujarat, \\ India \\ ${ }^{3}$ Nootan Pharmacy College, Visnagar, Gujarat, India \\ ${ }^{4}$ Kalol Institute of Pharmacy, Kalol, Gujarat, India
}

\begin{abstract}
The aims of this study were (1) to compare the in vitro dissolution profiles of oxcarbazepine-HP $\beta$-CD tablet formulations with those of marketed oxcarbazepine tablets, (2) to apply statistical models to evaluate each method in terms of easy application and usefulness, and (3) to identify the advantages and disadvantages of each method. The results show that the tablets containing hydroxypropyl $\beta$-cyclodextrin (HP $\beta$-CD) with sodium carboxymethylcellulose ( $\mathrm{NaCMC}$ ) exhibit faster release (1.93-fold) than marketed oxcarbazepine (OXO) tablets. From Weibull parameters, it was shown that $T_{d}$ is three times higher for OXC-HP $\beta$-CD with NaCMC tablets than for marketed oxcarbazepine tablets. The release kinetics of OXC complexed with HP $\beta-C D$ from different tablets was investigated using several mathematical equations. Model-independent methods including difference factor, $f_{1}$, and similarity factor, $f_{2}$; model-dependent methods; and ANOVA-based methods were used for the comparison of in vitro dissolution profiles. The results show that ANOVA-based methods and model-dependent methods are more discriminative than model-independent methods. Modelindependent methods seem to be easier to apply and interpret; only one value is obtained to describe the closeness of the two dissolution profiles. The application and evaluation of model-dependent methods are more complicated; these methods present an acceptable model approach to the true relationship between percent dissolved and time variables, including statistical assumptions that could be checked. Drug release data fit well to the Hixson-Crowell model. The drug release mechanism was a graphic of the cube root of the unreleased fraction of the drug with time. The Weibull model was more useful for comparing the release profiles. Weibull parameters were more sensitive to the differences between the two release kinetic data sets.
\end{abstract}

\section{INTRODUCTION}

$\mathrm{O}$ xcarbazepine is a poorly water-soluble, anti-epileptic drug according to the BCS system (Class II), and its dissolution is the rate-limiting step for absorption (1). Drug absorption from solid dosage forms after oral administration depends on the release of the drug substance from the drug product, the dissolution or solubilization of the drug under physiological conditions, and the permeability across the gastrointestinal tract. Because of the critical nature of the first two steps, in vitro dissolution may be relevant to the prediction of in vivo performance. Based on this general consideration, in vitro dissolution tests for immediate-release solid oral dosage forms are used (1) to assess the lot-to-lot quality of a drug product; (2) to assess the stability of the drug product; (3) to ensure continuing product quality and performance after certain changes (e.g., changes in the formulation, manufacturing process, site of manufacture,

\section{${ }^{5}$ Corresponding author.}

and scale-up of the manufacturing process); and (4) to develop new formulations.

In formulation development, dissolution testing can aid in the selection of excipients, the optimization of the manufacturing process, and the formulation of a test product to match the release of the reference product $(2,3)$. The solubility, permeability, dissolution, and pharmacokinetics of the drug substance are parameters used to set the dissolution method and specification. The methods for the comparison of in vitro dissolution profiles can be classified into three groups: methods based on analysis of variance (ANOVA) $(4,5)$, model-dependent methods (6), and model-independent methods (7-9).

In this context, the purpose of the present work was to enhance the solubility, hence dissolution, by using hydroxypropyl $\beta$-cyclodextrin alone and as a blend with various carriers such as NaCMC, PEG 6000, and PVP K-30. The discrimination of release profiles was compared with a marketed formulation using model-dependent and model-independent methods. Additionally, data analysis by fit factors was performed and compared with the results using the three methods. 
Table 1. Tablet Formulas of the OXC and OXC-HP $\beta-C D$ Binary Systems

\begin{tabular}{|c|c|c|c|c|c|}
\hline Ingredient & $\begin{array}{l}\text { Batch code (DCT) } \\
\text { Oxcarbazepine } \\
\text { Control (mg) }\end{array}$ & $\begin{array}{l}\text { Batch code (C1) } \\
\text { Oxcarbazepine- } \beta \\
\text { cyclodextrin (mg) }\end{array}$ & $\begin{array}{c}\text { Batch code (C2) } \\
\text { Oxcarbazepine- } \beta \\
\text { cyclodextrin + NaCMC } \\
(\mathrm{mg})\end{array}$ & $\begin{array}{c}\text { Batch code (C3) } \\
\text { Oxcarbazepine- } \beta \\
\text { cyclodextrin + PVP } \\
\text { K30 (mg) }\end{array}$ & $\begin{array}{c}\text { Batch code (C4) } \\
\text { Oxcarbazepine- } \beta \\
\text { cyclodextrin + PEG } \\
6000(\mathrm{mg})\end{array}$ \\
\hline OXC & 150 & 310 & 350 & 350 & 350 \\
\hline Avicel PH 101 & 450 & 130 & 120 & 120 & 120 \\
\hline Starch & 30 & 30 & 10 & 10 & 10 \\
\hline Talc & 10 & 10 & 10 & 10 & 10 \\
\hline Mg Stearate & 10 & 10 & 10 & 10 & 10 \\
\hline Total tablet weight & 650 & 650 & 650 & 650 & 650 \\
\hline
\end{tabular}

\section{METHODS}

All tablets were prepared using a direct compression method, and the OXC-HP $\beta$-CD complex was prepared by a kneading method. The formulation and batch codes of all tablets are described in Table 1.

\section{Dissolution Testing}

In vitro dissolution studies of prepared tablets were carried out in $900 \mathrm{~mL}$ of $0.1 \mathrm{~N} \mathrm{HCl}$ containing $0.25 \%$ sodium lauryl sulfate (SLS, pH 1.2) using USP Apparatus 2 (paddle method) with six replicates. The paddle rotation speed was $50 \mathrm{rpm}$, and a temperature of $37 \pm 1{ }^{\circ} \mathrm{C}$ was used in each test. In all experiments, $5 \mathrm{~mL}$ of dissolution sample was withdrawn at 5, 10, 15, 20, 30, and $45 \mathrm{~min}$, filtered using a $0.45-\mathrm{mm}$ Whatman filter, and replaced with an equal volume of fresh medium to maintain a constant total volume. Samples were assayed by UV spectrophotometry at $256.5 \mathrm{~nm}$ (Shimadzu UV-1202, Tokyo, Japan). Cumulative percentages of drug dissolved from the tablets were calculated (10).

\section{Applied Methods to Compare Dissolution Profiles Model-independent methods}

For the determination of dissolution data equivalence, FDA guidance documents recommend approaches such as the model-independent approach based on the calculation of difference $\left(f_{1}\right)$ and similarity $\left(f_{2}\right)$ factors (11), which is currently applied (8). The main advantage of the $f_{1}$ and $f_{2}$ equations is that they provide a simple way to compare the data. Nevertheless, both equations do not account for the variability or correlation structure of the data, and they are sensitive to the number of points used. From a statistical point of view, this method seems to be less discriminating than other methods, such as ANOVA and model-dependent methods. According to the FDA guidance (12), $f_{1}$ values of $0-15$ and $f_{2}$ values of $50-100$ ensure sameness or equivalence of the two dissolution profiles. In both equations, $R$ and $T$ represent the dissolution measurements at $P$ time points of the reference and test, respectively.

$$
\begin{gathered}
\left.f_{1}=\left\{\left[\sum_{i=1}^{P}|R-T|\right] / \sum_{i=1}^{P} R\right]\right\} \times 100 \\
f_{2}=50 \log \left\{\left[1+\left(\frac{1}{P}\right) \sum_{i=1}^{P}(R-T)^{2}\right]^{-1 / 2} \times 100\right\}
\end{gathered}
$$

Model-dependent methods

OXC release kinetics was analyzed by various mathematical models, which were applied considering the amounts of drug released from 0 to $30 \mathrm{~min}$. Table 2 presents the models tested (13-15). Depending on these estimations, suitable mathematical models to describe the dissolution profiles were determined.

The following plots were made: cumulative \% drug release versus time (zero-order kinetic model); log cumulative \% drug remaining versus time (first-order kinetic model); cumulative $\%$ drug release versus square root of time (Higuchi model); cube root of drug \% remaining in matrix versus time (Hixson-Crowell cube

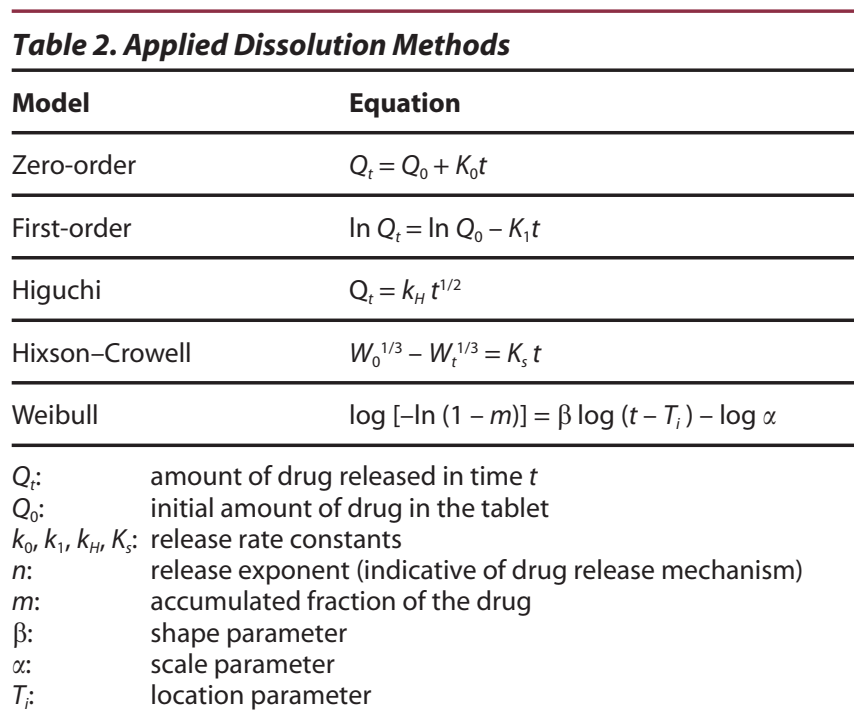

Dissolution Technologies | NOVEMBER 2008 


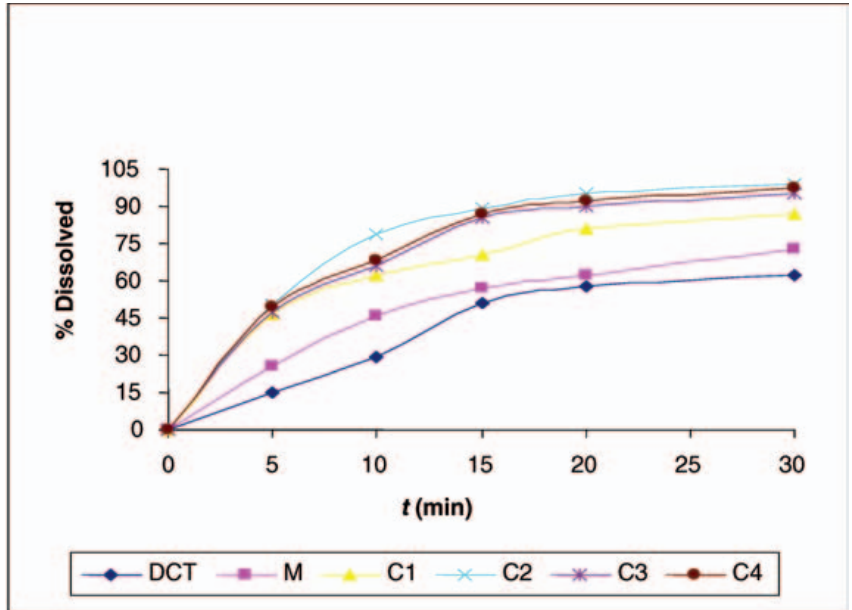

M: marketed oxcarbazepine tablet

Figure 1. Mean $(n=6)$ in vitro dissolution profiles of oxcarbazepine tablets.

root law); and log dissolved amount of drug versus log time (Weibull model) $(16,17)$.

\section{Statistical methods}

To compare the dissolution profiles of $\mathrm{C} 1-\mathrm{C} 4$ batches, two-way analysis of variance (ANOVA) followed by the Tukey test was performed using Sigma Stat software (Sigma Stat 2.03, SPSS, USA). In this method, the percent dissolved was the dependent variable, and time was the repeated factor.

\section{RESULTS AND DISCUSSION}

The in vitro dissolution profiles of the tablets are shown in Figure 1. Each data point represents a mean of six measurements for each product. All prepared batches except directly compressed tablets (DCT) complied with the dissolution specification, $Q$, stated in the USP (18) as dissolution not less than $80 \%$ of the labeled amount of OXC within $45 \mathrm{~min}$.

\section{Model-Independent Methods}

The dissolution profile of the marketed tablet is dissimilar to the profiles of DCT and C1-C4. The cumulative drug release of the marketed tablets was 1.15 times faster than that of the DCT tablet, and the tablets containing HP $\beta-C D$ with $\mathrm{NaCMC}$ exhibited 1.93 times faster release compared with marketed oxcarbazepine tablets. Therefore, it is concluded that formulations containing HP $\beta-C D$ alone and in a blend with $\mathrm{NaCMC}$ enhance the solubility and release of oxcarbazepine and seem superior to the marketed formulation.

The dissolution profile of the formulation containing pure drug (DCT) was dissimilar to those of batches $\mathrm{C} 1-\mathrm{C} 4$ when calculated using dissimilarity $\left(f_{1}\right)$ and similarity $\left(f_{2}\right)$ factors (results not shown). The dissimilarity $\left(f_{1}\right)$ and similarity $\left(f_{2}\right)$ factors for batches $\mathrm{C} 1-\mathrm{C} 4$ are given in
Table 3. $f_{1}$ and $f_{2}$ Values for Each Comparison

\begin{tabular}{lcll}
\hline Comparison & \multicolumn{1}{c}{$\boldsymbol{f}^{a}$} & $\boldsymbol{f}_{\mathbf{2}}$ & Dissolution Profile \\
\hline $\mathrm{DCT} \times \mathrm{M}$ & 21.55 or 17.73 & 47.49 & Dissimilar \\
\hline $\mathrm{C} 1 \times \mathrm{M}$ & 37.67 or 60.43 & 38.39 & Dissimilar \\
\hline $\mathrm{C} 1 \times \mathrm{C} 2$ & 19.14 or 16.07 & 42.26 & Dissimilar \\
\hline $\mathrm{C} 1 \times \mathrm{C} 3$ & 10.78 or 9.73 & 52.24 & Similar \\
\hline $\mathrm{C} 1 \times \mathrm{C} 4$ & 17.02 or 16.30 & 48.07 & Dissimilar \\
\hline $\mathrm{C} 2 \times \mathrm{C} 3$ & 7.02 or 7.55 & 57.95 & Similar \\
\hline $\mathrm{C} 2 \times \mathrm{C} 4$ & 4.30 or 4.49 & 64.90 & Similar \\
\hline $\mathrm{C} 3 \times \mathrm{C4}$ & 2.93 or 2.85 & 80.30 & Similar \\
\hline
\end{tabular}

${ }^{a}$ The first $f_{1}$ value is obtained when the first formulation on the left column is set as reference.

Table 3. It was observed that the dissolution profiles of $\mathrm{C} 2$, $\mathrm{C} 3$, and $\mathrm{C} 4$ could be considered equivalent to one other. It seemed that batches $\mathrm{C} 2-\mathrm{C} 4$ were formulated using additives along with HP $\beta-C D$, so the dissolution profiles of OXC-HP $\beta$-CD tablets prepared from various additives (NaCMC, PVP k-30 and PEG 6000) may be similar.

The dissolution of OXC from batch C2 was approximately $99.29 \%$ in $30 \mathrm{~min}$, so it was considered a most promising batch. The dissolution profiles of batch C1 (without additives) were expected to be dissimilar to batches $\mathrm{C} 2, \mathrm{C} 3$, and $\mathrm{C} 4$ (with additives). The results show the dissimilarity between batches $\mathrm{C} 1-\mathrm{C} 2$ and $\mathrm{C} 1-\mathrm{C} 4$ but similarity between batches $\mathrm{C} 1-\mathrm{C} 3$.

\section{Model-Dependent Methods}

Linearization of the OXC dissolution profiles using the equations in Table 2 would better characterize the differences found among all batches. Plots for various kinetic models are shown in Figures 2-6.

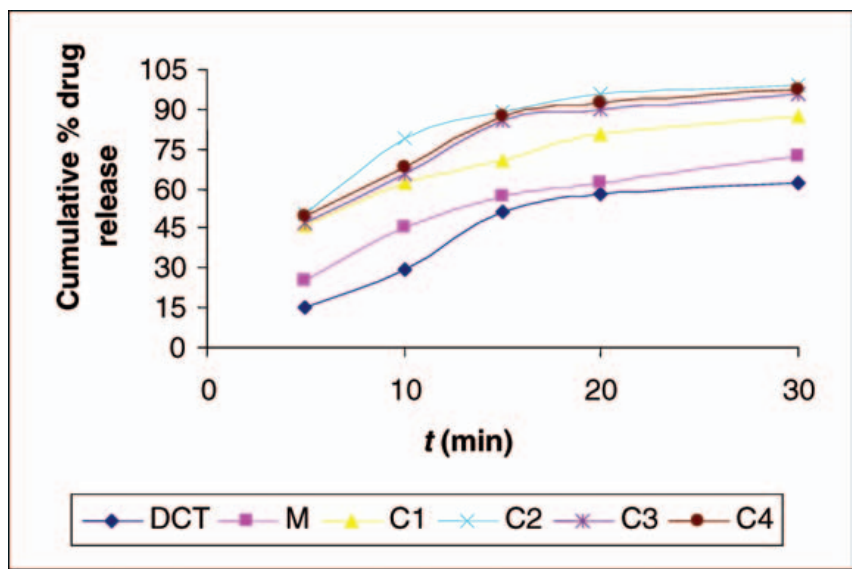

Figure 2. Zero-order plots for OXC formulations. 


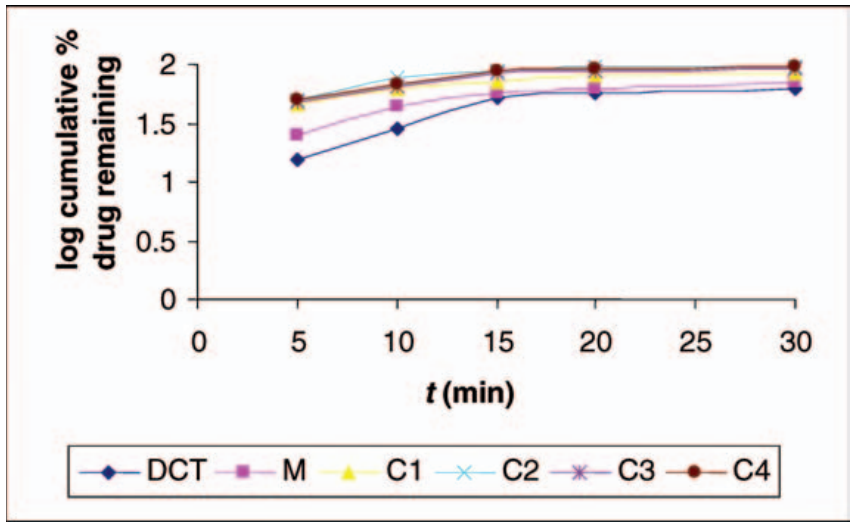

Figure 3. First-order plots for OXC formulations.

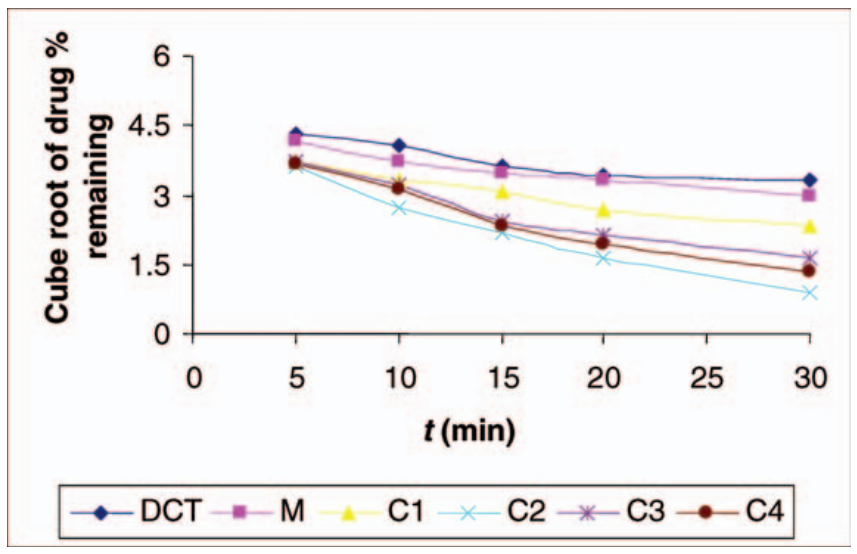

Figure 4. Hixson-Crowell plots for OXC formulations.

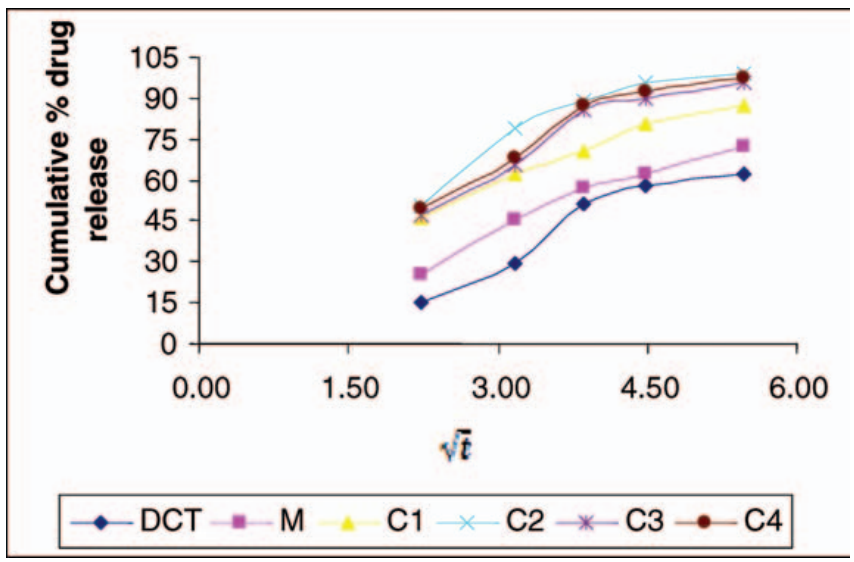

Figure 5. Higuchi plots for OXC formulations.

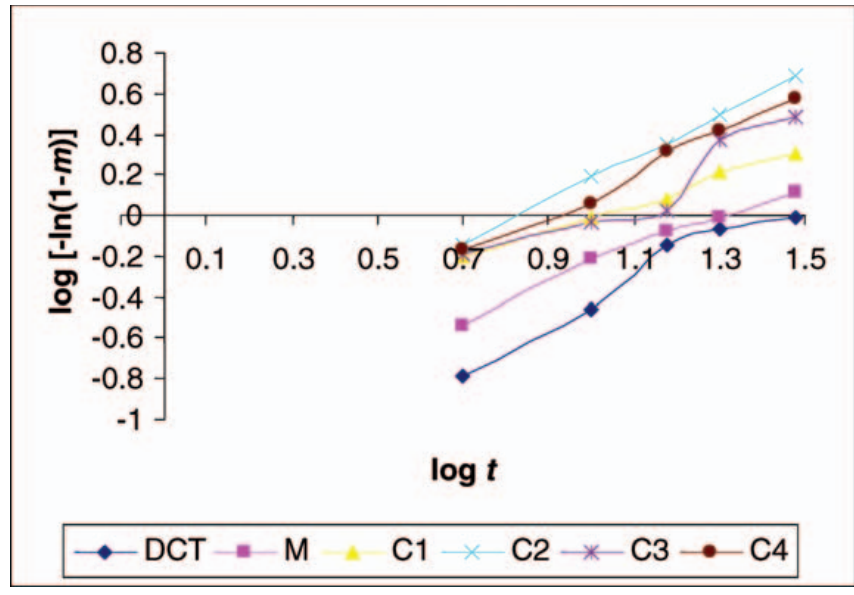

Figure 6. Weibull plots for OXC formulations.

Considering the determination coefficients $\left(R^{2}\right)$, the calculated zero-order and first-order models failed to fit all the batches. The Higuchi model fit C2 but not all other batches. This can indicate that the release kinetics of the OXC-HP $\beta$-CD NaCMC complex tablet may be dependent on the square root of time, as in the Higuchi model, which can describe the drug dissolution from several types of modified release systems (e.g., plastic and wax matrices) (19). The parameters and the $R^{2}$ values calculated by these models are summarized in Table 4.

The $R^{2}$ value of the Hixson-Crowell model may be applied to all the batches. The release mechanism of the drug from the dosage form is a function of the cube root of the unreleased fraction of the drug with time. According to Costa (19) and Niebergall et al. (20), the geometric shape of the tablet diminishes proportionally over time. It is assumed that the release rate is limited by the dissolution rate of drug particles. Although the Weibull distribution cannot adequately characterize the dissolution kinetic properties of the drug, it can describe the dissolution curve in terms of applicable parameters. The linearity of the Weibull plots is shown in Figure 6. The shape parameter, $\beta$, characterizes the curve as either exponential $(\beta=1)$, S-shaped with upward curvature followed by a turning point $(\beta>1)$, or as one with a steeper initial slope than is consistent with the exponential $(\beta<1)(13)$.

The calculated Weibull $\beta$ parameter was $<1$ for batches $M$ and C1-C4 (Table 4), which indicates a parabolic curve with steeper initial slope than is consistent with the exponential. As was observed from the $\beta$ values presented in Table 4, batches C2-C4 show similarity in terms of dissolution curve shape. The $\beta$ value for batch $C 1$ is 0.6701 , which is much different from those of C2-C4 (almost 0.9). The calculated Weibull $\beta$ parameter was $>1$ for the batch containing pure drug (DCT), which indicates 


\begin{tabular}{|c|c|c|c|c|c|c|}
\hline Dissolution Model & DCT & M & C1 & C2 & C3 & C4 \\
\hline Zero-order $K_{0}$ & 1.9209 & 1.7681 & 1.5829 & 1.7775 & 1.8817 & 1.8796 \\
\hline$R^{2}$ & 0.8415 & 0.8888 & 0.9129 & 0.7537 & 0.8242 & 0.8223 \\
\hline First-order $K_{0}$ & 0.0234 & 0.0162 & 0.0104 & 0.0104 & 0.0115 & 0.0112 \\
\hline$R^{2}$ & 0.7595 & 0.7817 & 0.8606 & 0.6886 & 0.7747 & 0.7722 \\
\hline Higuchi $K_{0}$ & 15.54 & 14.27 & 12.665 & 14.72 & 15.34 & 15.34 \\
\hline$R^{2}$ & 0.9146 & 0.9575 & 0.9701 & 0.8582 & 0.9087 & 0.9084 \\
\hline Hixson-Crowell $K_{0}$ & -0.043 & -0.0445 & -0.0569 & -0.1081 & -0.0849 & -0.0954 \\
\hline$R^{2}$ & 0.8711 & 0.9455 & 0.9675 & 0.9648 & 0.9349 & 0.9537 \\
\hline \multicolumn{7}{|l|}{ Weibull } \\
\hline$R^{2}$ & 0.9496 & 0.9807 & 0.9926 & 0.9988 & 0.9829 & 0.9885 \\
\hline$\beta$ & 1.0638 & 0.8246 & 0.6701 & 0.9986 & 0.9135 & 0.9575 \\
\hline$T_{d}(\min )$ & 25.40 & 20.25 & 10.31 & 6.91 & 8.27 & 7.69 \\
\hline$a$ & 31.22 & 11.94 & 4.77 & 7.99 & 6.89 & 7.35 \\
\hline$t_{50 \%}(\mathrm{~min})$ & 14.13 & 13.10 & 8.01 & 4.96 & 7.61 & 7.31 \\
\hline
\end{tabular}

a complex release mechanism with an S-shaped curve with upward curvature followed by a turning point. The time parameter, $T_{d}$, can be calculated from $a$ and $b$ parameters $\left(a=\left(T_{d}\right)^{b}\right)$ and represents the time interval necessary to dissolve $63.2 \%$ of the drug (13). $T_{d}$ for DCT was approximately $2.46,3.67,3.07$, and 3.30 times higher than for the $\mathrm{C} 1, \mathrm{C} 2, \mathrm{C} 3$, and C4 formulations, respectively, which reflects the dissimilarity between DCT and the prepared formulations (C1-C4). For batch C2, a minimum time was required to dissolve $63.2 \%$ drug as compared with other formulations. A higher $T_{d}$ value indicates slower release. Therefore, it was concluded that batch $C 2$ gave faster release as compared with all other formulations. From the Weibull parameters, it was shown that $T_{d}$ is three times higher for OXC-HP $\beta$-CD with $\mathrm{NaCMC}$ tablets than for the marketed oxcarbazepine tablet. Taken together, the analysis performed by the Weibull model suggests that OXC release from formulations containing OXC-HP $\beta$-CD complexes is different from the formulation containing only OXC (DCT). Among the studied models, Weibull was considered a good model once it possessed parameters that are sensitive to the ranges of dissolution profiles.

\section{Statistical Methods}

From the results of the model-dependent (Weibull parameters) and model-independent methods, it was clear that the dissolution profiles of batch DCT were quite different from those of the other batches $\mathrm{C} 1-\mathrm{C} 4$; hence, DCT was not considered for comparison by two-way ANOVA.

The results of two-way ANOVA for batches C1-C4 are shown in Table 5. From the results of Table 5, it was concluded that (1) the differences in the mean values among the treatment groups are greater than would be expected by chance, (2) the calculated $F$ value (15.073) is greater than tabulated $F$ value (3.490), and (3) there is a statistically significant difference $(P=0.0002)$. To evaluate the differences among the four batches, the Tukey test was performed on the results of ANOVA. Results of the Tukey test show that there is a statistically significant difference between batches $C 1$ and $C 2$ as well as between 
Table 5. Results of Two-Way ANOVA

\begin{tabular}{lccccc}
\hline Source of Variation & SS & Df & MS & F & P-value \\
\hline Rows & 5620.445 & 4 & 1405.111 & 134.57657 & 7.385 \\
\hline Columns & 472.1386 & 3 & 157.3795 & 15.073254 & 0.0002259 \\
\hline Error & 125.2918 & 12 & 10.44098 & 3.4902996 \\
\hline Total & 6217.875 & 19 & & & \\
\hline
\end{tabular}

SS: Sum of squares

Df: Degree of freedom

MS: Mean squares

C1 and C4, which is in accordance with the results of the model-independent method. Results of the Tukey test also show that statistically significant differences exist between batches $\mathrm{C} 1$ and $\mathrm{C} 3$. However, batches $\mathrm{C} 1$ and $\mathrm{C} 3$ are similar by the model-independent method $\left(f_{2}=48\right)$. Therefore, further analysis was done using paired sample $t$-test on batches $\mathrm{C} 1-\mathrm{C} 2, \mathrm{C} 1-\mathrm{C} 3$, and $\mathrm{C} 1-\mathrm{C} 4$. The results of the $t$-test show statistically significant differences between batches $\mathrm{C} 1-\mathrm{C} 2, \mathrm{C} 1-\mathrm{C} 3$, and $\mathrm{C} 1-\mathrm{C} 4$, which confirms the results of the Tukey test. Thus, it was concluded that the statistical methods are more discriminative than the modelindependent method for the comparison of the dissolution profiles of OXC-HP $\beta$-CD tablet formulations.

\section{CONCLUSION}

A fast-release oxcarbazepine tablet was prepared successfully by using a blend of HP $\beta-C D$ with $\mathrm{NaCMC}$, which enhanced dissolution release rate via solubility and achieved the required dissolution profile. Drug release from this formulation corresponds best to the Hixson-Crowell model, which indicates the release of drug from the surface of granular matrices. The $\alpha$ and $\beta$ parameters of the Weibull model suggest a meaningful comparison of level (location) and homogeneity in profile shape. From among the models used for the comparison of the in vitro dissolution profiles, it was concluded that model-independent methods are simpler, but discrimination between profiles was found using model-dependent and Weibull models.

\section{REFERENCES}

1. Patel, N. V.; Chotai, N. P.; Patel, M. P. Tablet formulation studies on an oxcarbazepine- $\beta$ cyclodextrin binary system. Die Pharmazie 2008, 63 (4), 275-281.

2. Carrico, C. K. Workshop report-AAPS: USP workshop on dissolution calibration and testing. Pharm. Res. 1996, 13, 6-9.

3. Shah, V. P.; Lesko, L. J.; Fan, J.; Fleischer, N.; Handerson, J.; Malinowski, H.; Makary, M.; Ouderkirk, L.; Roy, S.; Sathe, P.; Singh, G. J. P.; Tillman, L.; Tsong, Y.; Williams,
R. L. FDA Guidance for Industry: Dissolution Testing of Immediate Release Solid Oral Dosage Forms. Dissolution Technol. 1997, 4, 15-22.

4. Mauger, J. W.; Chilko, D.; Howard, S. On the analysis of the dissolution data. Drug Dev. Ind. Pharm. 1986, 12, 969-992.

5. Polli, J. E.; Rekhi, G. S.; Augsburger, L. L.; Shah, V. P. Methods to compare dissolution profiles and a rationale for wide dissolution specifications for metoprolol tartrate tablets. J. Pharm. Sci. 1997, 86, 690-700.

6. Sathe, P. M.; Tsong, Y.; Shah, V. P. In vitro dissolution profile comparison: statistics and analysis, model dependent approach. Pharm. Res. 1996, 13, 1799-1803.

7. Podczeck, F. Comparison of in vitro dissolution profiles by calculating mean dissolution time (MDT) or mean residence time (MRT). Int. J. Pharm. 1993, 97, 93-100.

8. Moore, J. W.; Flanner, H. H. Mathematical comparison of dissolution profiles. Pharm. Technol. 1996, 6, 64-74.

9. Shah, V. P.; Tsong, Y.; Sathe, P.; Liu, J.-P. In vitro dissolution profile comparison-statistics and analysis of the similarity factor, $f_{2}$. Pharm. Res. 1998 , 15, 889-896.

10. Corrigan, O. I.; Stanley, T. Mechanism of drug dissolution rate enhancement from $\beta$ cyclodextrin-drug systems. J. Pharm. Pharmacol. 1982, 34, 621-626.

11. Gudrun, F. Guidelines on dissolution profile comparison. Drug Inf. J. 2001, 35, 865-874.

12. Dissolution Testing of Immediate Release Solid Oral Dosage Forms; Guidance for Industry; U.S. Department of Health and Human Services, Food and Drug Administration, Center for Drug Evaluation and Research (CDER), U.S. Government Printing Office: Washington, DC, 1997. http://www.fda.gov/ cder/guidance/1713bp1.pdf (accessed Sept 29, 2008). 
13. Langenbucher, F. Linearization of dissolution rate curves by the Weibull distribution. J. Pharm.

Pharmacol. 1972, 24, 979-981.

14. Gibaldi, M.; Feldman, S. Establishment of sink conditions of dissolution rate determinations. J. Pharm. Sci. 1967, 56, 1238-1242.

15. Wagner, J. G. Interpretation of percent dissolved-time plots derived from in vitro testing of conventional tablets and capsules. J. Pharm. Sci. 1969, 58, 12531257.

16. Harris, M. S.; Jaweria, T.; Hamid, A.; Merchant. Evaluation of drug release kinetics from ibuprofen matrix tablets using HPMC. Pak. J. Pharm. Sci. 2006, 19 (2), 119-124.

17. Coasta, P.; Sousa, L. J. M. Modeling and comparison of dissolution profiles. Eur. J. Pharm. Sci. 2001, 13, 123-133.

18. United States Pharmacopeia and National Formulary USP 23-NF 18; The United States Pharmacopeial Convention, Inc.: Rockville, MD, 1997.

19. Costa, P. An alternative method to the evaluation of similarity factor in dissolution testing. Int. J. Pharm. 2001, 220, 77-83.

20. Niebergall, P. J.; Milosovich, G.; Goyan, J. E. Dissolution rate studies II. Dissolution of particles under conditions of rapid agitation. J. Pharm. Sci. 1963, 52, 236-241. 